\title{
Ultra-Small Superparamagnetic Iron Oxide Nanoparticles Made to Order
}

\author{
Benyettou $\mathrm{F}^{1}$, Milosevic $\mathrm{I}^{2}$, Olsen $\mathrm{JC}^{3}$, Motte $\mathrm{L}^{2 *}$ and Trabolsi $\mathrm{A}^{1}$
}

${ }^{1}$ New York University Abu Dhabi, Abu Dhabi, UAE

${ }^{2}$ Université Paris 13, Sorbonne Paris Cité, Laboratoire CSPBAT, CNRS, (UMR 7244), F-93017, Bobigny, France

${ }^{3}$ School of Sciences, Indiana University Kokomo, Kokomo, IN 46904, USA

\begin{abstract}
A fast, efficient and green microwave-assisted synthesis of ultra-small, superparamagnetic iron oxide nanoparticles is reported. By controlling the temperature and heating mode of a polyol reduction using triethylene glycol (TREG) as a green, high-boiling solvent, ultra-small nanoparticles (2-4 nm) exhibiting robust superparamagnetic behavior were obtained. The sizes of the nanoparticles were determined by TEM and DLS measurements. Using a ligand exchange process, the TREG molecules on the surface of the smallest nanoparticles $(2 \mathrm{~nm})$ were successfully replaced with Alendronate, an anti-cancer drug molecule, effectively transforming the nanoparticles into a potential theranostic agent.
\end{abstract}

Keywords: Iron oxide nanoparticles; Polyol synthesis; Microwave; Nanocarriers; Drug delivery

\section{Introduction}

Superparamagnetic iron oxide nanoparticles (SPIONs) with tailored surface chemistry have emerged as a promising nanomaterial for numerous biomedical applications [1-6] including MRI [7-10], tissue repair [11], immunoassay [12,13], detoxification of biological fluids [11], hyperthermia [14], drug delivery [15], and cell manipulation [16-18]. In general, to be most effective, the nanoparticles must have high magnetization values. To be nontoxic and biocompatible, they must be small and have a narrow size distribution [19-22]. Both magnetization and size are strongly determined by the method of nanoparticle synthesis, and many protocols have been explored such as co-precipitation [23], sol-gel [24], thermal decomposition [25], micro emulsion [26], and hydrothermal methods [27,28]. However, in contrast to these well-established approaches, the use of microwave irradiation represents a relatively new strategy for nanoparticle synthesis and surface functionalization [29-32].

Microwave-assisted chemistry boasts competitive advantages over conventional methods and is becoming increasingly popular in all areas of synthesis [33]. This unique technology allows reactions to proceed in very short times, and often with higher selectivity, yield, and energy efficiency than methods that rely on conventional heating [34]. Advantages of microwave-assisted nanomaterials synthesis have been demonstrated with polymer microspheres [35], metallic nanoparticles [36], metal oxides [37], and quantum-dots [38]. The application of the microwave technique to iron oxide nanoparticle fabrication is due, and, in fact, several microwave-assisted syntheses of iron oxide nanoparticles have been reported; however, in these preliminary cases, the protocols have either required toxic additives [39], or the nanoparticles that were produced lacked monodispersity [39], or required a phase transfer step to confer water solubility [40].

The polyol synthesis (which is also known as the thermal decomposition method) of metal oxide nanoparticles is a forced hydrolysis of transition metal salts [40-43]. Polyols are used as solvents because (i) they can act as reducing polar solvents and (ii) their high boiling points allow for the solubilization and reduction of a large number of metal salts. For example, decomposition of the iron oxide precursor, iron (III) acetyl acetonate $\left(\mathrm{Fe}(\mathrm{acac})_{3}\right)$ in triethylene glycol (TREG) gives access to high quality, superparamagnetic, and monodisperse iron oxide nanoparticles [44-46]. TREG solvent has been widely used as a green solvent for various organic syntheses due to its low toxicity [47]. However, despite the fact that TREG itself is practical and environmentally benign, many procedures that rely on it as a solvent also involve severe reaction conditions including elevated temperatures (up to $200^{\circ} \mathrm{C}$ ), long reaction times (some more than 10 hours), and/or uncommon equipment such as a sealed autoclave [47].

In this paper, we describe a fast, convenient, and green, synthetic route to ultra-small superparamagnetic iron oxide nanoparticles (2-4 $\mathrm{nm}$ ) that combines the advantages of both the microwave chemistry and the polyol synthesis. We also provide a comparison between nanoparticles prepared by this combined technique and those produced by a method involving conventional thermal decomposition. Also, we note that our microwave-assisted method provides nanoparticles that are stable, and easily dispersed in water and that functionalization of the surface of these nanoparticles with alendronate (Scheme 1), an antitumor molecule, was successful, making them a potential material for drug delivery and release.

\section{Materials and Methods}

Tri(ethylene glycol) (TREG, 99\%), iron(III) acetylacetonate (Fe(acac) 3 , 97\%), and ethyl acetate were purchased from Sigma-Aldrich and used as received.

\section{Synthesis of (4-Amino-1-hydroxy-1-phosphonobutyl) phosphonic acid (Alendronate)}

Alendronate was synthesized according to the general procedure [48] for linear aliphatic BPs and characterized by ${ }^{1} \mathrm{H}$ and ${ }^{31} \mathrm{P}$ NMR. 4 -aminobutyric acid $(150 \mathrm{mmol})$ and phosphorous acid $(150 \mathrm{mmol})$

*Corresponding author: Motte L, Université Paris 13, Sorbonne Paris Cité, Laboratoire CSPBAT, CNRS, (UMR 7244), F-93017, Bobigny, France, Tel: 330148-387-707; Fax: 330-148-387-625; E-mail: laurence.motte@univ-paris13.fr

Received December 11, 2012; Accepted December 18, 2012; Published December 21, 2012

Citation: Benyettou F, Milosevic I, Olsen JC, Motte L, Trabolsi A (2012) Ultra-Smal Superparamagnetic Iron Oxide Nanoparticles Made to Order. J Bioanal Biomed S5: 006. doi:10.4172/1948-593X.S5-006

Copyright: (c) 2012 Benyettou F, et al. This is an open-access article distributed under the terms of the Creative Commons Attribution License, which permits unrestricted use, distribution, and reproduction in any medium, provided the original author and source are credited. 


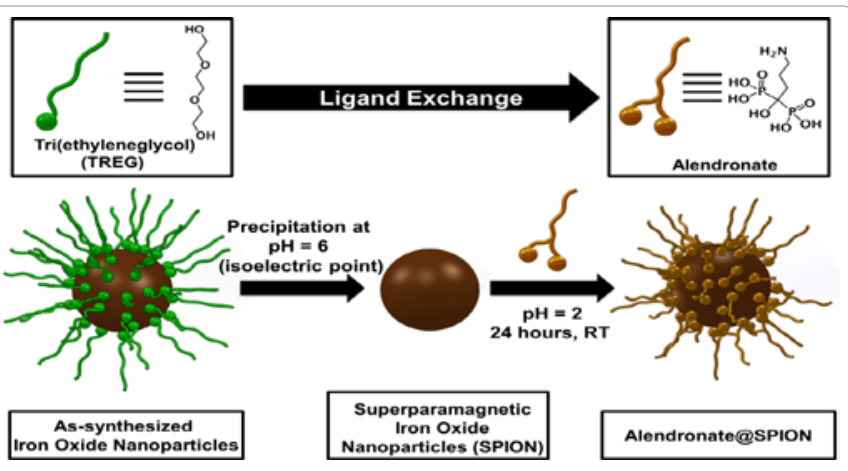

Scheme 1: A graphical representation of the ligand exchange process TREGAlendronate on the surface of the superparamagnetic iron oxide nanoparticles (SPIONs). SPIONs originally obtained with TREG molecules, provide an outstanding platform on which different molecules can be attached to their surface.

were introduced in a three-necked round-bottom flask under inert atmosphere followed by $30 \mathrm{ml}$ of methane sulfonic acid. After heating at $65^{\circ} \mathrm{C}$ for $1 \mathrm{~h}$, phosphorus trichloride was added slowly and the reaction was allowed to proceed overnight at $65^{\circ} \mathrm{C}$. The resulting yellow viscous reaction mixture was cooled to room temperature, and quenched with $500 \mathrm{ml}$ of ice-cold water. The $\mathrm{pH}$ was adjusted to 4.3 with an aqueous $\mathrm{NaOH}$ solution $(0.5 \mathrm{M})$, and the obtained white precipitate was collected by filtration. This solid was washed five times with a mixture of methanol/water (95:5) and freeze-dried to finally obtain alendronate (82\%). RMN ${ }^{31} \mathrm{P}\left\{{ }^{1} \mathrm{H}\right\}\left(80.9 \mathrm{MHz}, \mathrm{H}_{3} \mathrm{PO}_{4} / \mathrm{D}_{2} \mathrm{O}\right): 18.47 . \mathrm{RMN}{ }^{1} \mathrm{H}(500$ $\left.\mathrm{MHz}, \mathrm{D}_{2} \mathrm{O}\right): 3.046$ (m, 2H), 2.017 (m, 4H). I.R.: 1540, 1172, $1052 \mathrm{~cm}^{-1}$.

\section{Synthesis of iron oxide nanoparticles}

Water-soluble iron oxide nanoparticles were prepared by the thermal decomposition process. $\mathrm{Fe}(\mathrm{acac})_{3}\left(10^{-3} \mathrm{M}\right)$ was dissolved in 5 $\mathrm{ml}$ of hydrophilic TREG media magnetically stirred without a flow of argon and then quickly heated to the desired temperature. The solution was cooled with an ice bath. The nanoparticles were precipitated by addition of $10 \mathrm{ml}$ of ethyl acetate and then isolated by centrifugation at $4000 \mathrm{rpm}$ for $20 \mathrm{~min}$. The obtained precipitate was re-dispersed in water and further precipitated, followed by centrifugation. This washing procedure was repeated 5 times. The washed particles were dispersed in acidic water to obtain a stable aqueous ferrofluid suspension. The temperature of the reaction was varied in order to study its effect on the nanoparticles size and magnetism.

Synthetic details of the two methods used for the fabrication of iron oxide nanoparticle, (conventional heating and microwave synthesis), are detailed below.

\section{Synthesis carried out in conventional heating}

The reaction mixture was first heated to a desired temperature and then heated for a specified time. After heating, the resulting precipitate was cleaned by following the procedure described above and redispersed in acidic water $\left(\mathrm{HCl}, 10^{-2} \mathrm{M}\right)$ to form a clear brown colloidal dispersion.

\section{Synthesis realized under microwaves heating}

The homogeneous dispersion of $\mathrm{Fe}(\mathrm{acac})_{3}$ in TREG was transferred into a $10 \mathrm{ml}$ vessel with a crimp cap, heated by microwave irradiation of $2.45 \mathrm{GHz}$ (CEM Discovery, CEM Inc. USA), and the other reaction parameters were modulated, applying a maximum power of $300 \mathrm{~W}$.
The power was automatically adjusted to heat the sample to the set reaction parameters (temperature and time). The precipitate obtained was separated by adding brine $(10 \mathrm{~mL})$, followed by centrifugation at $4000 \mathrm{rpm}$ for $20 \mathrm{~min}$. The supernatant from this first centrifugation was discharged and the precipitate was dispersed in $10 \mathrm{~mL}$ of ethyl acetate and centrifuged again at $4000 \mathrm{rpm}$ for $20 \mathrm{~min}$. The precipitate was redispersed in acidic water $\left(\mathrm{HCl}, 10^{-2} \mathrm{M}\right)$ to form a clear orange colloidal dispersion.

\section{Nanoparticle surface functionalization with alendronate}

The nanoparticles were precipitated at $\mathrm{pH} 6$ and cleaned to remove excess TREG. This procedure was repeated 5 times. Alendronate (40 $\mathrm{mg}$ ) was solubilized in $1 \mathrm{ml}$ of water and the solution was added dropwise to the cleaned nanoparticles, and the $\mathrm{pH}$ was adjusted to 2 . The reaction mixture was stirred for 1 hour at room temperature. The Alendronate coated particles were cleaned by repeated precipitations at $\mathrm{pH}=2$.

\section{Nanoparticle characterization}

Size and morphology of the nanoparticles were determined by transmission electron microscopy (TEM, FEI CM10 Microscope) and dynamic light scattering (DLS) (Zetasizer Nano-ZS, Malvern Instruments). Each sample was analyzed at room temperature with diluted ferrofluid ([Fe] $=10^{-3} \mathrm{~mol} \cdot \mathrm{L}^{-1}$ ) at $\mathrm{pH}=2$. Surface coating of the nanoparticles were characterized by Fourier transform infrared spectroscopy (FTIR, Varian 3100). Magnetic properties of the nanoparticles were studied using a MIAtek reader (Magnetic Immunoassays Technology), which measured a signal proportional to the third derivative of magnetization at zero magnetic field. The detection method was based on the nonlinear magnetization of SPION. An alternating magnetic field was applied to the sample at two different frequencies $f_{1}=100 \mathrm{kHz}$ and $\mathrm{f}_{2}=100 \mathrm{~Hz}$ having amplitudes of 10 and 200 Oe, respectively. The response of the sample was measured at combinatorial frequencies, e.g., $\mathrm{f}=\mathrm{f}_{1} \pm 2 \mathrm{f}_{2}$ [49]. The weight percentage of Alendronate molecules on the surface of the nanoparticles was determined by thermogravimetric analysis (TGA). Solid samples (10 mg) under $\mathrm{N}_{2}(\mathrm{~g})$ flux were characterized with a SDT Q600 TA Instruments analyzer at a heating rate of $5^{\circ} \mathrm{C} / \mathrm{min}$ over a temperature range of $35-700^{\circ} \mathrm{C}$.

\section{Results and Discussion}

\section{Nanoparticle size and shape}

The influence of reaction temperature and heating mode on nanoparticle size was studied. Figures $1 \mathrm{~A}$ and $1 \mathrm{~B}$ show the TEM images of the nanoparticles obtained after reactions (15 minutes each) that were carried out at different temperatures and with different heating methods (conventional or microwave).

Under conventional heating, nanoparticles having an average diameter of $1 \mathrm{~nm}$ were detected only in reactions performed at temperatures of $175^{\circ} \mathrm{C}$ or greater, figure $1 \mathrm{~A}$. Typically, polyol syntheses are performed at higher temperatures $\left(250-350^{\circ} \mathrm{C}\right)$, and for a longer times ( $\sim 10$ hours). Under these conditions, the size of the nanoparticles can be tuned within the range of $4 \mathrm{~nm}$ to approximately $50 \mathrm{~nm}[50,51]$. In contrast, our results show that under microwave heating (15 minutes, $\left.\left[\mathrm{Fe}(\mathrm{acac})_{3}\right]=10^{-3} \mathrm{M}\right)$, the kinetics of nanoparticle formation are altered. As shown in figure $1 \mathrm{~B}$, globular nanoparticles with a diameter of 2 $\mathrm{nm}$ were formed at temperatures as low as $140^{\circ} \mathrm{C}$. When the reaction temperature was raised, the size of the nanoparticles (which retained the same spherical morphology) increased linearly (Figure 1C). Such 
experiments show that microwave heating, causes faster nucleation and leads to highly uniform nanoparticles, highlighting the key role that temperature plays in nanoparticle formation and growth [52]. Furthermore, these results suggest that nucleation rate is more sensitive to temperature variation than growth rate, which essentially depends on the reaction time [53]. Finally, with microwave heating, the temperature is homogeneous in the reactor vessel which may explain the narrow size distribution of the particles produced (Figure 1B, inset). Thus, a moderate temperature $\left(140^{\circ} \mathrm{C}\right)$ and a short reaction time (15 min) under microwave heating were sufficient to produce small (2 $\mathrm{nm})$, monodisperse iron oxide nanoparticles.

Figure 1C shows DLS size measurements (made in aqueous acidic solution) of the microwave-produced nanoparticles. The hydrodynamic sizes of the nanoparticles increases from $4 \mathrm{~nm}$ at $140^{\circ} \mathrm{C}$ to $7 \mathrm{~nm}$ at $200^{\circ} \mathrm{C}$. The sizes measured by DLS are slightly larger than those measured by TEM, a difference that can be explained by the presence of TREG molecules and the hydrogen bonded water molecules on the nanoparticle surface.

Microwave heating was found to have a noticeable effect on nanoparticle size in polyol synthesis and allowed short reaction times and greater control if the size of the iron oxide nanoparticle.

\section{Magnetic characterization}

Measurement of the magnetic properties of the nanoparticles was carried out using a MIAtek reader (Magnetic Immunoassays Technology). Figure 2 shows the signal proportional to the third derivative of magnetization at zero magnetic field and room temperature of nanoparticles produced by conventional or microwave heating. The nanoparticles produced by conventional heating were found to have lower magnetism which can be explained by their smaller size [53]. Typically, nanoparticles with 2 to $30 \mathrm{~nm}$ in size are expected to be superparamagnetic. In contrast, the MIAtek signals of the particles synthesized by microwave heating were dramatically enhanced from 400 to 23,000 MIAtek units/mg, for reaction temperatures that ranged from 140 to $200^{\circ} \mathrm{C}$, respectively. This increase in signal intensity is likely a consequence of the particles increased size, their decreased surface to volume ratio, as well as modification of their crystalline phase. These results provide evidence for what we believe is the first example of a microwave-assisted synthesis of ultra-small superparamagnetic iron oxide nanoparticles $(2-4 \mathrm{~nm})$.

\section{Surface chemistry and reactivity}

The as-synthesized nanoparticles were first characterized by FTIR (Figure 3A). The peaks at 2962-2809, 1632, 1455, 1350, 1251 and 1063 $\mathrm{cm}^{-1}$ are characteristic of the $\mathrm{C}-\mathrm{H}$ stretching, $\mathrm{O}-\mathrm{H}$ stretching, $\mathrm{C}-\mathrm{H}$ bending, $\mathrm{C}-\mathrm{O}$ bending and $\mathrm{O}-\mathrm{H}$ bending vibrations, respectively, and are attributed to the adsorbed TREG molecules on the particles surface [45]. A FTIR spectrum (Figure 3B) of a sample of cleaned nanoparticles lacks these signals and indicates that the TREG was removed from the particles surface.

The cleaned surface of the microwave-synthesized $\left(140^{\circ} \mathrm{C}, 15\right.$ minutes, $2 \mathrm{~nm}$ ) nanoparticles was functionalized with Alendronate. The passivation process was performed in acidic media ( $\mathrm{pH} 2)$ at room temperature, and the nanoparticles' surface was characterized by FTIR and TGA.

The FTIR spectra of the nanoparticles coated with Alendronate (Figure 3C) as compared to the free Alendronate (Figure 3D) show large differences within the P-O stretching region $\left(1200-900 \mathrm{~cm}^{-1}\right)$, indicating
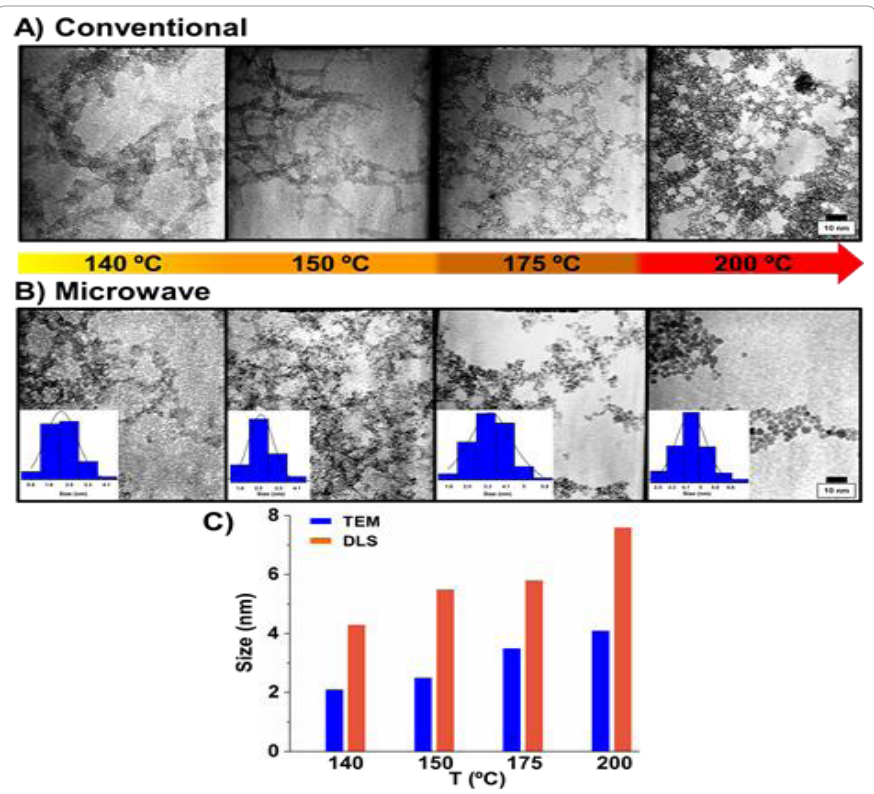

Figure 1: TEM images of the products of reactions carried out at different temperatures for 15 minutes using A) conventional and B) microwave heating C) TEM (blue) versus DLS (orange) size measurements of the microwaveproduced nanoparticles. B inset/size distribution of the particles produced under microwave heating at different temperature for 15 minutes.

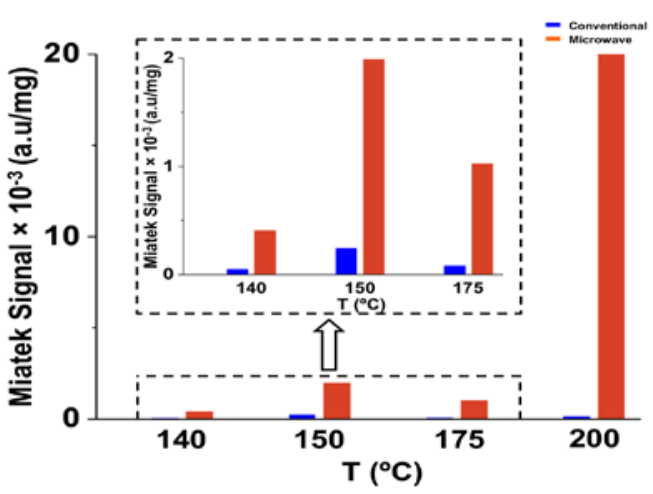

Figure 2: MIAtek signal of the obtained nanoparticles at different temperature using conventional (blue) vs. microwave (orange) heating.

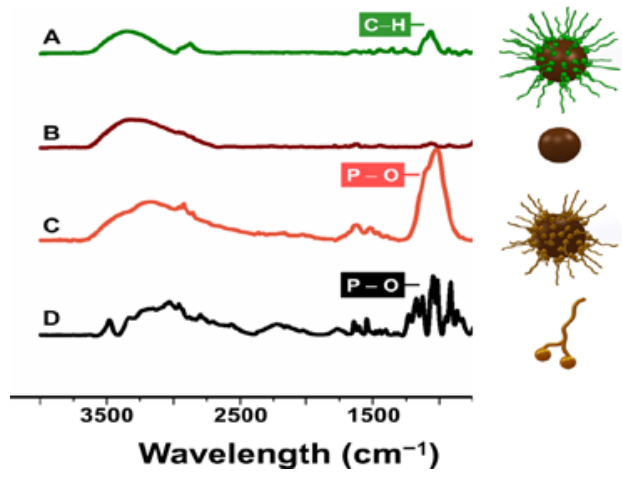

Figure 3: FTIR spectra of microwave assisted iron oxide nanoparticles $\left(140^{\circ} \mathrm{C}\right.$, 15 minutes, $2 \mathrm{~nm}$ ) A) as-synthesized nanoparticles, B) clean nanoparticles, C) nanoparticles coated with alendronate, and D) free alendronate. 


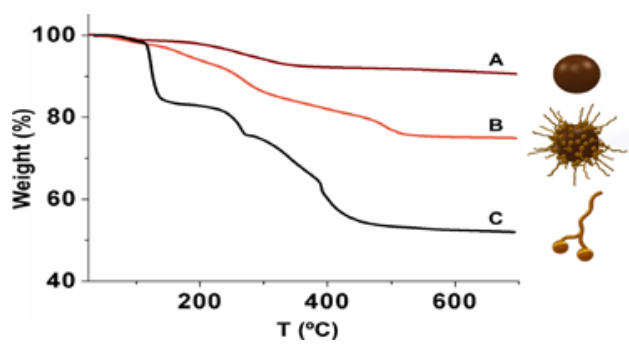

Figure 4: TGA curves of Microwave assisted iron oxide nanoparticles $\left(140^{\circ} \mathrm{C}\right.$, 15 minutes, $2 \mathrm{~nm}$ ) A) clean nanoparticles, B) nanoparticles coated with alendronate and C) free alendronate.

successful adsorption of phosphonic acids onto the iron oxide surface. Moreover, the amine bending vibration band $\left(1540 \mathrm{~cm}^{-1}\right)$ for Alendronate was not affected.

In order to quantify the amount of Alendronate on the surface of the nanoparticles, TGA of the Alendronate coated ones as well as free Alendronate molecule are shown in figures $4 \mathrm{~A}$ and $4 \mathrm{~B}$, respectively. The $200-500^{\circ} \mathrm{C}$ temperature range was chosen as the Alendronate desorption zone. Below $200^{\circ} \mathrm{C}$, the slight weight loss is due to solvent evaporation. Above $500^{\circ} \mathrm{C}$, weight loss is due to iron oxide. The TGA curve (Figure 4B) of the nanoparticles coated with Alendronate shows two different weight losses (Figure $4 \mathrm{C}$ ), one at $100^{\circ} \mathrm{C}$ corresponding to water removal $(2.36 \%)$ and a second one characteristic of Alendronate combustion (20.68\%). Finally, the residual weight corresponds to iron oxides $(75.96 \%)$. Using these weight loss percentage values, we calculated that there were on average 10 Alendronate molecules bound to each nanoparticle.

\section{Conclusion}

We have developed a new, fast and green synthetic route to ultrasmall, superparamagnetic iron oxide nanoparticles via microwave heating. Iron oxide nanoparticles with small hydrodynamic sizes (2-4 $\mathrm{nm})$, reasonable polydispersity, and excellent magnetic properties have been synthesized using moderate reaction temperature $\left(140^{\circ} \mathrm{C}\right)$ and very fast reaction time ( $15 \mathrm{~min})$. We have also demonstrated the strong influence that temperature and uniform microwave heating on nanoparticles formation. The nanoparticles obtained were easily dispersible in water and their surface was coated with biocompatible molecules, in particular, Alendronate, an anticancer drug of the bisphosphonate family. The sum of these results strongly motivates us to consider these nanoparticles as potential drug carriers and simultaneously to assess their properties as MRI contrast agents.

\section{References}

1. Reddy LH, Arias JL, Nicolas J, Couvreur P (2012) Magnetic nanoparticles: design and characterization, toxicity and biocompatibility, pharmaceutical and biomedical applications. Chem Rev 112: 5818-5878.

2. Jain KK (2005) Role of nanobiotechnology in developing personalized medicine for cancer. Technol Cancer Res Treat 4: 645-650.

3. Sengupta S, Sasisekharan R (2007) Exploiting nanotechnology to target cancer. Br J Cancer 96: 1315-1319.

4. Wang MD, Shin DM, Simons JW, Nie S (2007) Nanotechnology for targeted cancer therapy. Expert Rev Anticancer Ther 7: 833-837.

5. Wu HC, Wang TW, Bohn MC, Lin FH, Spector M (2010) Novel Magnetic Hydroxyapatite Nanoparticles as Non-Viral Vectors for the Glial Cell LineDerived Neurotrophic Factor Gene. Adv Funct Mater 20: 67-77.

6. Gupta AK, Wells S (2004) Surface-modified superparamagnetic nanoparticles for drug delivery: preparation, characterization, and cytotoxicity studies. IEEE Trans Nanobioscience 3: 66-73.

7. Na HB, Song IC, Hyeon T (2010) Inorganic Nanoparticles for MRI Contrast Agents. Adv Mater 21: 2133-2148.

8. Lin W, Hyeon T, Lanza GM, Zhang M, Meade TJ (2009) Magnetic Nanoparticles for Early Detection of Cancer by Magnetic Resonance Imaging. MRS Bulletin 34: 441-448.

9. Lalatonne Y, Paris C, Serfaty JM, Weinmann P, Lecouvey M, et al. (2008) Bis-phosphonates-ultra small superparamagnetic iron oxide nanoparticles: a platform towards diagnosis and therapy. Chem Commun (Camb) 2553-2555.

10. Benyettou F, Lalatonne Y, Chebbi I, Benedetto DM, Serfaty JM, et al (2011) A multimodal Magnetic Resonance Imaging Nanoplatform for Cancer Theranostics. Phys Chem Chem Phys 13: 10020-10027.

11. Gupta AK, Gupta M (2005) Synthesis and surface engineering of iron oxide nanoparticles for biomedical applications. Biomaterials 26: 3995-4021.

12. Motte L, Benyettou F, de Beaucorps C, Lecouvey M, Milosevic I, et al (2011) Multimodal superparamagnetic nanoplatform for clinical applications: immunoassays, imaging \& therapy. Faraday Discuss 149: 211-225.

13. de Montferrand C, Lalatonne Y, Bonnin D, Motte L, Monod P (2012) Non-linear magnetic behavior around zero field of an assembly of superparamagnetic nanoparticles. Analyst 137: 2304-2308.

14. Hergt R, Hiergeist R, Hilger I, Kaiser WA, Lapatnikov Y, et al. (2004) Maghemite nanoparticles with very high AC-losses for application in RF-magnetic hyperthermia. J Magn Magn Mater 270: 345-357.

15. Benyettou F, Chebbi I, Motte L, Seksek O (2011) Magnetoliposome for Alendronate Delivery. J Mater Chem 21: 4813-4820.

16. Amendola V, Meneghetti M, Granozzi G, Agnoli S, Polizzi S, et al. (2011) Topdown synthesis of multifunctional iron oxide nanoparticles for macrophage labelling and manipulation. J Mater Chem 21: 3803-3813.

17. Roca AG, Costo R, Rebolledo AF, Veintemillas-Verdaguer S, Tartaj P, et al (2009) Progress in the preparation of magnetic nanoparticles for applications in biomedicine J Phys D Appl Phys 42: 224002-224012.

18. Benyettou F, Chebbi I, Motte L, Seksek O (2011) Magnetoliposome for Alendronate Delivery. J Mater Chem 21: 4813-4820.

19. Plassat V, Renoir JM, Autret G, Marsaud V, Menager C, et al. (2011) Systemic Magnetic Targeting of Pure-Antiestrogen-Loaded Superparamagnetic Nanovesicles for Effective Therapy of Hormone-Dependent Breast Cancers. J Bioanal Biomed S2: 001

20. Taranta M, Naldi I, Grimaldi S, Salvini L, Claudio PP, et al. (2011) Magnetically Driven Bioreactors as new Tools in Drug Delivery. J Bioanal Biomed S5: 002.

21. Benyettou F, Hardouin J, Marc Lecouvey, Jouni H, Motte L (2012) PEGylated Versus Non-PEGylated $\mathrm{FFe}_{2} \mathrm{O}_{3} @$ Alendronate Nanoparticles. J Bioanal Biomed 4: 39-45.

22. Laurent S, Forge D, Port M, Roch A, Robic C, et al. (2008) Magnetic iron oxide nanoparticles: synthesis, stabilization, vectorization, physicochemical characterizations, and biological applications. Chem Rev 108: 2064-2110.

23. Vayssieres L (2009) On the Effect of Nanoparticle Size on Water-Oxide Interfacial Chemistry. J Phys Chem C 113: 4733-4736.

24. Lu Y, Yin Y, Mayers B, Xia Y (2002) Modifying the Surface Properties of Superparamagnetic Iron Oxide Nanoparticles through A Sol-Gel Approach. Nano Letters 2: 183-186.

25. Murray CB, Norris DJ, Bawendi MG (1993) Synthesis and characterization of nearly monodisperse $\mathrm{CdE}$ ( $\mathrm{E}=$ sulfur, selenium, tellurium) semiconductor nanocrystallites. J Am Chem Soc 115: 8706-8715.

26. Langevin D (1992) Micelles and Microemulsions. Annu Rev Phys Chem 43 341-369.

27. Daou TJ, Pourroy G, Begin-Colin S, Greneche JM, Ulhaq-Bouillet C, et al. (2006) Hydrothermal Synthesis of Monodisperse Magnetite Nanoparticles. Chem Mater 18: 4399-4404.

28. Sun S, Zeng H (2002) Size-controlled synthesis of magnetite nanoparticles. Am Chem Soc 124: 8204-8205

29. Benyettou F, Guenin E, Lalatonne Y, Motte L (2011) Microwave Assisted Nanoparticle Surface Functionalization. Nanotechnology 22: 1-7. 
Citation: Benyettou F, Milosevic I, Olsen JC, Motte L, Trabolsi A (2012) Ultra-Small Superparamagnetic Iron Oxide Nanoparticles Made to Order. J Bioanal Biomed S5: 006. doi:10.4172/1948-593X.S5-006

30. Milosevic I, Jouni H, David C, Warmont F, Bonnin D, et al. (2011) Facile Microwave Process in Water for the Fabrication of Magnetic Nanorods. J Phys Chem C 115: 18999-19004.

31. Guenin E, Hardouin J, Lalatonne Y, Motte L (2012) Bivalent alkynebisphosphonate as clickable and solid anchor to elaborate multifunctional iron oxide nanoparticles with microwave enhancement. J Nanopart Res 14: 965.

32. Donegan KP, Godsell JF, Tobin JM, O'Byrne JP, Otway DJ, et al. (2011) Microwave-assisted synthesis of icosahedral nickel nanocrystals. CrystEngComm 13: 2023-2028.

33. Solano E, Perez-Mirabet L, Martinez-Julian F, Guzman R, Arbiol J, et al. (2012) Facile and efficient one-pot solvothermal and microwave-assisted synthesis of stable colloidal solutions of $\mathrm{MFe}_{2} \mathrm{O}_{4}$ spinel magnetic nanoparticles. J Nanopart Res 14: 1034.

34. Pascu O, Carenza E, Gich M, Estrade S, Peiro F, et al. (2012) Surface Reactivity of Iron Oxide Nanoparticles by Microwave-Assisted Synthesis; Comparison with the Thermal Decomposition Route. J Phys Chem C 116: 15108-15116.

35. An Z, Tang W, Hawker CJ, Stucky GD (2006) One-step microwave preparation of well-defined and functionalized polymeric nanoparticles. J Am Chem Soc 128: 15054-15055.

36. Kawasaki H, Kosaka Y, Myoujin Y, Narushima T, Yonezawa T, et al. (2011) Microwave-assisted polyol synthesis of copper nanocrystals without using additional protective agents. Chem Commun (Camb) 47: 7740-7742.

37. Ding K, Miao Z, Liu Z, Zhang Z, Han B, et al. (2007) Facile synthesis of high quality $\mathrm{TiO} 2$ nanocrystals in ionic liquid via a microwave-assisted process. $J$ Am Chem Soc 129: 6362-6363.

38. He Y, Lu HT, Sai LM, Lai WY, Fan QL, et al. (2006) Synthesis of CdTe nanocrystals through program process of microwave irradiation. J Phys Chem B 110: 13352-13356.

39. Guardia P, Labarta A, Batlle X (2011) Tuning the Size, the Shape, and the Magnetic Properties of Iron Oxide Nanoparticles. J Phys Chem C 115: 390-396.

40. Fievet F (2000) Fine Particles: Synthesis, Characterization, and Mechanism of Growth. Sugimoto (Ed.), Surfactant science series, vol. 92, Marcel Dekker, Inc., New York 460 4: 179

41. Poul L, Ammar S, Jouini N, Fievet F (2003) Synthesis of inorganic compounds (metal, oxide and hydroxide) in polyol medium: a versatile route related to the sol-gel process. J Sol-Gel Sci Tech 26: 261-265.
42. Pinna N, Grancharov S, Beato P, Bonville P, Antonietti M, et al. (2005) Magnetite Nanocrystals: Nonaqueous Synthesis, Characterization, and Solubility. Chem Mater 17: 3044-3049.

43. Pinna N, Niederberger M (2008) Surfactant-free nonaqueous synthesis of metal oxide nanostructures. Angew Chem Int Ed Engl 47: 5292-5304.

44. Dahal N, García S, Zhou J, Humphrey SM (2012) Beneficial Effects of Microwave-Assisted Heating versus Conventional Heating in Noble Metal Nanoparticle Synthesis. ACS Nano 6: 9433-9446.

45. Maity D, Kale SN, Kaul-Ghanekar R, Xue JM, Ding J (2009) Studies of magnetite nanoparticles synthesized by thermal decomposition of iron (III) acetylacetonate in tri(ethylene glycol). J Magn Magn Mater 321: 3093-3098.

46. Cao SW, Zhu YJ, Chang J (2008) $\mathrm{Fe}_{3} \mathrm{O}_{4}$ polyhedral nanoparticles with a high magnetization synthesized in mixed solvent ethylene glycol-water system. New J Chem 32: 1526-1530.

47. Suk FC, Suh CP, Ching HT (2011) Green Synthesis of Magnetite Nanoparticles (via Thermal Decomposition Method) with Controllable Size and Shape. J Mater Environ Sci 2: 299-302.

48. Kieczykowski GR, Jobson RB, Melillo DG, Reinhold DF, Grenda VJ (1995) Preparation of (4-hino-1-Hydroxybuty1idene)bisphosphonic Acid Sodium Salt, MK-217 (Alendronate Sodium). An Improved Procedure for the Preparationof 1-Hydroxy-1,I-bisphosphonicAcids. J Org Chem 60: 8310-8312.

49. Geinguenaud F, Souissi I, Fagard R, Motte L, Lalatonne Y (2012) Electrostatic assembly of a DNA superparamagnetic nano-tool for simultaneous intracellular delivery and in situ monitoring. Nanomedicine 8: 1106-1115.

50. Jun YW, Lee JH, Cheon J (2008) Chemical design of nanoparticle probes for high-performance magnetic resonance imaging. Angew Chem Int Ed Engl 47 5122-5135.

51. Hu F, Jia Q, Li Y, Gao M (2011) Facile synthesis of ultrasmall PEGylated iron oxide nanoparticles for dual-contrast T1- and T2-weighted magnetic resonance imaging. Nanotechnology 22: 1-7.

52. Xu S, Luo Z, Han Y, Guo J, Wang C (2012) Ultrafast microwave-assisted synthesis of MCNCs with high saturation magnetization and sustained aqueous stability. RSC Adv 2: 2739-2742.

53. Demortière A, Panissod P, Pichon BP, Pourroy G, Guillon D, et al. (2011) Sizedependent properties of magnetic iron oxide nanocrystals. Nanoscale 3: 225232.

This article was originally published in a special issue, Biomedicine Pharmacotherapy handled by Editor(s). Dr. Taichun Qin, University of Texas, USA 